\title{
Antibodies against keratinocyte antigens other than desmogleins 1 and 3 can induce pemphigus vulgaris-like lesions
}

\author{
Vu Thuong Nguyen, ${ }^{1}$ Assane Ndoye, ${ }^{1}$ Leonard D. Shultz, ${ }^{2}$ \\ Mark R. Pittelkow, ${ }^{3}$ and Sergei A. Grando ${ }^{1}$ \\ ${ }^{1}$ Department of Dermatology, University of California at Davis, School of Medicine, Davis, California, USA \\ ${ }^{2}$ The Jackson Laboratory, Bar Harbor, Maine, USA \\ ${ }^{3}$ Department of Dermatology, Mayo Clinic, Rochester, Minnesota, USA \\ Address correspondence to: Sergei A. Grando, 4860 Y Street, Suite 3400, Sacramento, California 95817, USA. \\ Phone: (916) 734-6057; Fax: (916) 734-6793; E-mail: sagrando@ucdavis.edu. \\ Received for publication May 11, 2000, and accepted in revised form November 6, 2000.
}

Pemphigus is an autoimmune disease of skin adhesion associated with autoantibodies against a number of keratinocyte antigens, such as the adhesion molecules desmoglein (Dsg) 1 and 3 and acetylcholine receptors. The notion that anti-Dsg antibodies alone are responsible for blisters in patients with pemphigus vulgaris (PV) stems from the ability of rDsg1 and rDsg3 to absorb antibodies that cause PV-like skin blisters in neonatal mice. Here, we demonstrate that PV IgGs eluted from rDsg1-Ig-His and rDsg3-Ig-His show similar antigenic profiles, including the 38-, 43-, 115-, and 190-kDa keratinocyte proteins and a non-Dsg 3 130-kDa polypeptide present in keratinocytes from Dsg 3 knockout mouse. We injected into Dsg 3-lacking mice the PV IgGs that did not cross-react with the $160-\mathrm{kDa}$ Dsg 1 or its $45-\mathrm{kDa}$ immunoreactive fragment and that showed no reactivity with recombinant Dsg 1 . We used both the $D s g 3^{\text {null }}$ mice with a targeted mutation of the $D s g 3$ gene and the "balding" $D s g 3^{\text {bal }} / D s g 3^{\text {bal }}$ mice that carry a spontaneous null mutation in Dsg3. These PV IgGs caused gross skin blisters with PV-like suprabasal acantholysis and stained perilesional epidermis in a fishnet-like pattern, indicating that the PV phenotype can be induced without anti-Dsg 3 antibody. The anti-Dsg 1 antibody also was not required, as its presence in PV IgG does not alter the PV-like phenotype in skin organ cultures and because pemphigus foliaceus IgGs produce a distinct phenotype in $D s g 3^{\text {null }}$ mice. Therefore, mucocutaneous lesions in PV patients could be caused by non-Dsg antibodies.

J. Clin. Invest. 106:1467-1479 (2000).

\section{Introduction}

In pemphigus vulgaris (PV), blisters develop on oral mucosa. Mucosal lesions are often followed by skin involvement. The deep intraepidermal cleft occurs between the basal cells and the overlaying spinous keratinocytes. In pemphigus foliaceus (PF), the oral mucosa is usually not involved, and cutaneous erosive lesions develop owing to a superficial epidermal split localized to the stratum granulosum. The pathophysiological mechanism causing autoimmune pemphigus is unknown and still being intensively investigated. To date, a catalogue of self-antigens, demonstrated by various authors and detection techniques to react uniquely with pemphigus IgGs, includes approximately 20 molecules with different relative molecular masses, namely: $12,18,33,47,50,52,55,59,66,67,68,75,78$, $80,85,102,105,160,180,185 / 190$, and $210 \mathrm{kDa}$ (reviewed in ref. 1). The number of detectable target molecules varies from patient to patient and depends on the sensitivity of the detection technique, i.e., immunoblotting versus immunoprecipitation. Hypothetically, some of these bands may represent degradation products of pemphigus antigens having higher native molecular weights. The number of detectable pemphigus antigens can be substantially reduced by altering the sensitivity of the technique, as is performed when the keratinocyte protein suspension, the source of antigens, is first preabsorbed with normal human serum and then used in an immunoprecipitation assay with PV and PF sera $(2,3)$. Only a few protein bands remain, including the pairs of $85 / 130$ and $85 / 160 \mathrm{kDa}$ that were considered to represent the pathophysiologically important targets of PV and PF autoimmunity, respectively (4). Likewise, the number of clones detected in a $\lambda$ gt 11 keratinocyte cDNA library by PV IgG was reduced by substituting the whole PV IgG fraction with the affinity-purified IgG from a single band, the 130kDa keratinocyte polypeptide (5).

The $130-\mathrm{kDa}$ PV antigen was reported to be a novel keratinocyte desmoglein (Dsg) 3 (5); the 160-kDa PF antigen, Dsg 1 (6); and the $85-\mathrm{kDa}$ antigen, recognized by both PV and PF IgGs, was identified as the adhesion molecule plakoglobin (7). Autoantibodies to these adhesion molecules in pemphigus were interpreted as direct, cause-and-effect pathogenesis with autoantibody binding to an adhesion molecule inducing a dis- 
ease of skin dyshesion (8-10). The broad spectrum variety of clinical and histological manifestations of autoimmune pemphigus has been explained by some investigators as an interplay between Dsg 1 and Dsg 3 antibodies. These antibodies are proposed to cause pemphigus directly by disrupting desmosomal junctions within the upper and lower epidermal compartments (11), based on the predominant differential expression of the $D s g 1$ and $D s g 3$ genes in the upper and lower epidermis, respectively $(12,13)$. However, a deletion mutation in the $\mathrm{NH}_{2}$-terminal extracellular domain of Dsg 1 results in the dominantly inherited condition of striate palmoplantar keratoderma without any intraepidermal dyshesion (14). Similar thickening of the stratum corneum without skin blistering also occurs in Dsg 3-truncated transgenic mice (15). Furthermore, no spontaneous gross skin blistering is observed in the $D s g 3^{\text {null }}$ mouse with a targeted mutation of the Dsg3 gene or the "balding" $D s g 3^{\text {bal }} / D s g 3^{\text {bal }}$ mouse with a spontaneous null mutation in the Dsg3 gene (16, 17). Interestingly, even in P-cadherin/Dsg 3 double knockout mice neither spontaneous nor trauma (skin rubbing)-induced gross and microscopic alterations of the integrity of the epidermis can be found (18).

Preabsorption of patients' sera with recombinant Dsg1-Ig and Dsg3-Ig chimeric baculoproteins eliminate disease-causing activities of PF and PV IgG fractions, respectively. Further, IgGs eluted from recombinant Dsg molecules elicit acantholysis and gross skin blisters in neonatal BALB/c mice (19-23). Surprisingly, although both the recombinant protein representing the extracellular epitope of Dsg 3 and a chimeric baculoprotein combining sequences of the extracellular epitope of Dsg 3 and of the Fc portion of human IgG1 effectively absorb anti-Dsg 3 antibody from PV sera, only absorption on the chimeric baculoprotein can eliminate the antibodies capable of causing gross skin blisters in neonatal mice. The explanation for this phenomenon is that addition of the Fc IgG1 portion assists the Dsg 3 portion to fold properly and acquire an "active" conformation; however, confirmation that $r D s g 3-I g-H i$ is absorbs only antibodies to Dsg 3 was not provided.

Using Dsg 3-deficient mice, we have recently demonstrated that the PV IgGs lacking anti-Dsg 1 antibody can (a) produce a PV-like, fishnet staining pattern of the epidermis when used in indirect immunofluorescence (IIF) reactions; and (b) induce clinical and histological signs of PV when injected intraperitoneally into Dsg3 $3^{\text {null }}$ neonates (1). Furthermore, we have shown rDsg3-Ig-His can absorb the non-Dsg 3 antibodies that are pathogenic in $D s g 3^{\text {null }}$ neonates (24). These results indicated that non-Dsg 3 PV antibodies mediate acantholysis but could not eliminate a possibility that the undetected anti-Dsg 1 antibody contributed to acantholytic activity of test PV IgGs in Dsg $3^{\text {null }}$ pups, because (a) $25-60 \%$ of patients with PV have both anti-Dsg 1 and anti-Dsg 3 antibodies, as demonstrated by immunoprecipitation $(25,26)$, immunoblotting
(27-29), and immunohistochemistry (30); (b) spread of lesions from the oral mucosa to the skin in one patient with PV was reported to be associated with the appearance of anti-Dsg 1 antibody (31); and, most importantly, (c) absorption of PV IgGs with rDsg1 was reported to eliminate the disease-causing activity, whereas the anti-Dsg 1 PV IgG was suggested to play a critical role in induction of PV-like deep suprabasilar acantholysis in Dsg3 $3^{\text {mull }}$ neonates (32).

In this study, we attempt to resolve the controversy about the role of anti-Dsg antibodies in pemphigus. First, we demonstrate that antibodies targeting Dsg 1 and Dsg 3 are not essential for induction of PV-like lesions in neonatal mice and that PV antibodies to other keratinocyte self-antigens are sufficient for causing gross skin blisters. Second, we reveal the lack of monospecificity of the rDsg1-Ig-His and rDsg3-Ig-His chimeric baculoproteins for anti-Dsg 1 and anti-Dsg 3 antibodies, respectively. Third, we document that PV IgG fraction containing anti-Dsg 3 antibody without anti-Dsg 1 antibody or PV IgG fraction containing both anti-Dsg 1 and anti-Dsg 3 antibodies produce deep suprabasilar acantholysis in either wild-type or Dsg3 ${ }^{\text {null }}$ mice, whereas PF IgG fraction containing anti-Dsg 1 antibody without anti-Dsg 3 antibody produces subcorneal acantholysis localized to the granular layer. The cumulative results obtained in this study indicate that non-Dsg antibodies are sufficient to induce PV-like pathology in neonatal mice. Lesions in patients with PV may therefore result from cumulative and/or synergistic effects of a set of autoantibodies targeting different specific self-antigens on the keratinocyte cell surface.

\section{Methods}

Pemphigus and control sera, and IgG fractions. The results reported here were obtained in experiments using sera and IgG fractions from patients with well-established PV and PF, and healthy volunteers. This study had been approved by the University of California Davis Human Subjects Review Committee. The diagnosis of PV or PF was made based on the results of both comprehensive clinical and histological examinations and immunological studies, including direct immunofluorescence (DIF), IIF on various epithelial substrates, immunoblotting, and immunoprecipitation, following standard protocols (33). The serum IgG fractions were isolated using $40 \%$ ammonium sulfate followed by dialysis against PBS (Life Technologies Inc., Gaithersburg, Maryland, USA), lyophilized and reconstituted in PBS as detailed elsewhere (1). The protein concentration was determined using the Micro BCA kit (Pierce Chemical Co., Rockford, Illinois, USA). The serum level of rheumatoid factor was measured by a standard nephelometric technique using a commercially available antigen (Kit P/N 465320; Beckman Instruments Inc., Brea, California, USA). According to the reference range used in the clinical laboratory of University of California Davis Medical Center, normal values do not exceed $20 \mathrm{IU} / \mathrm{ml}$. 
Enhanced sensitivity immunoprecipitation assay. Cultures of epidermal keratinocytes used for metabolic radioactive labeling were established from normal human neonatal foreskins and grown to approximately $95 \%$ confluence in $150 \mathrm{~cm}^{2}$ flasks (Corning Costar, Cambridge, Massachusetts, USA) in serum-free keratinocyte growth medium (KGM; Life Technologies Inc.) containing 0.09 $\mathrm{mM} \mathrm{Ca}{ }^{2+}$ at $37^{\circ} \mathrm{C}$ in a humid $5 \% \mathrm{CO}_{2}$ incubator, as described previously (34). Cultured keratinocyte monolayers were metabolically labeled for 16 hours at $37^{\circ} \mathrm{C}$ with $100 \mu \mathrm{Ci} / \mathrm{mL}\left[{ }^{35} \mathrm{~S}\right]$ methionine $(1,000 \mathrm{Ci} / \mathrm{mmol}$; Amersham Life Science Inc., Arlington Heights, Illinois, USA) in $1.8 \mathrm{mM} \mathrm{Ca}^{2+}$ labeling medium, and the $\left[{ }^{35} \mathrm{~S}\right]$ methionine-labeled proteins were separated by centrifugation and used as a source of naturally folded keratinocyte proteins in an immunoprecipitation assay (25). The immune complexes were precipitated with a protein A-Sepharose suspension (Sigma Chemical Co., St. Louis, Missouri, USA), washed, and resolved on SDS-PAGE gels. The gels were fixed, enhanced, and the radioactivity was analyzed using the storage phosphor autoradiography feature of the Storm system (Molecular Dynamics, Mountain View, California, USA), as described by us previously (35). The presence of Dsg 1 antibody in test sera was investigated using the $45-\mathrm{kDa}$ tryptic fragment of Dsg 1 representing its immunoreactive epitope (36). Briefly, $\left.{ }^{35} \mathrm{~S}\right]$ methionine-labeled keratinocytes were homogenized in $10 \mathrm{mM}$ Tris-buffered saline containing $0.025 \% \mathrm{NaN}_{3}$, and $20 \mathrm{mM} \mathrm{Ca}^{2+}$ (TBS-Ca) buffer containing $0.25 \%$ bovine trypsin (Sigma Chemical Co.) and then incubated for 1 hour at $37^{\circ} \mathrm{C}$. The trypsinized homogenate was treated with $1 \mathrm{mM}$ PMSF to stop the reaction, centrifuged at $40,000 \mathrm{~g}$, and the supernatant was passed through a Concanavalin A Sepharose column (Con-A) (EY Laboratories Inc., San Mateo, California, USA). The Con-A-bound glycoproteins containing the 45-kDa immunoreactive epitope of Dsg 1 were eluted with 0.2 M $\alpha$-methylmannoside (Sigma Chemical Co.), dialyzed against TBS-Ca, concentrated by lyophilization and used in enhanced sensitivity immunoprecipitation assay (ESIA) as a source of antigen.

ELISA. The reactivity of test sera with the extracellular portions of the Dsg 1 or Dsg 3 peptide sequences that reportedly represent pathogenic epitopes of the PV or PF antigens (37-39) was determined using Dsg 1and Dsg 3-coated ELISA plates purchased from MBL (Nagoya, Japan), including the positive and the negative controls, and following the protocols provided by the manufacturer. All serum samples were tested in duplicate or triplicate on at least two different occasions, using different lots of ELISA plates, and the results were expressed as ELISA scores, or index values (IVs), calculated as follows: IV = (OD sample - OD negative control)/(OD positive control - OD negative control) $\times 100$. As recommended by the manufacturer, a serum sample was considered to be positive for Dsg 1 or Dsg 3 antibody if the IV exceeded 20.

The samples of the PV, PF and normal human control sera used in this study were also independently tested in the laboratory of L.A. Diaz at Medical College of Wisconsin using the Dsg 1 ELISA developed in this laboratory.

In vitro model of pemphigus. The standard protocols for treatment of normal human skin organ cultures with pemphigus serum $(40,41)$ were modified to eliminate known shortcomings. The samples of normal facial skin freshly removed from adult Caucasians undergoing surgical procedures were freed of fat and clotted blood, and 3-mm-diameter samples were obtained using a standard skin biopsy punch. These skin samples were rinsed in PBS, placed in plastic tubes containing ice-cold KGM without supplements, transported to the laboratory, and used in experiments immediately. The skin samples, containing epidermis and papillary and reticular dermis, were placed into the wells of the standard Ubottom 96-well cell-and-tissue culture plates (FalconBecton Dickinson Labware, Lincoln Park, New Jersey, USA), and $200 \mu \mathrm{L}$ of test serum was added to each well. Each serum was tested in triplicate skin samples. The dishes were incubated at $37^{\circ} \mathrm{C}$ in a humid $5 \% \mathrm{CO}_{2}$-containing atmosphere for 24, 36, 48, 72, and 96 hours. After each incubation period, the skin samples were harvested and examined by both light microscopy and DIF. In vivo model of pemphigus. The skin blisters were induced in neonatal mice by passive transfer of serum IgG fraction (42). This study had been approved by the University of California Davis Review Committee on the Use of Animals in Research. The IgGs were injected intraperitoneally through a 30 -gauge needle into 10 - to 12-hour-old pups at the doses specified in Results. The neonates in each progeny always received the same amount of test or control IgG. The latter was isolated from normal human serum purchased from Sigma Chemical Co. Both Dsg 3-containing BALB/c mice, and Dsg 3-deficient Dsg $3^{\text {null }}$ and C57BL/6 Dsg $3^{\text {bal }} / D s g 3^{\text {bal }}$ mice were used (17). The integument of mice lacking Dsg 3 is normal at birth, making these neonates a suitable model for induction of pemphigus phenotype in passive transfer experiments $(1,32)$. In each litter, the lack of Dsg 3 in pups with induced blisters was confirmed by genotyping at the end of each passive transfer experiment. PCR was used to amplify the genomic sequences from the DNA isolated from pieces of mouse tails. The genotyping of $D s g 3^{\text {null }}$ mice was performed using PCR primers and reaction conditions described by us previously (1). The genotyping of $D s g 3^{\text {bal }} / D s g 3^{\text {bal }}$ mice was performed by sequencing the PCR product that amplified a portion of the exon 14 of the $D s g 3$ gene containing the 2275 insT functional null mutation. The sense $5^{\prime}$-gccatagcatgaactgttag$3^{\prime}$ and antisense $5^{\prime}$-gttggettgtcttgtgagtt- $3^{\prime}$ primers (BioSynthesis Inc., Lewisville, Texas, USA) were used in PCR and the amplification condition included preheating at $94^{\circ} \mathrm{C}$ for 4 minutes; hot start with Taq DNA polymerase (Promega Corp., Madison, Wisconsin, USA), then 35 cycles at $94^{\circ} \mathrm{C}$ for 1 minute, $60^{\circ} \mathrm{C}$ for 1 minute, and $72^{\circ} \mathrm{C}$ for 3 minutes. The knockout $D s g 3^{\text {null }}$ mice were homozygous for a targeted mutation of the Dsg3 gene, and "balding" $D s g 3^{b a l} / D s g 3^{\text {bal }}$ mice were homozygous for a spontaneous null mutation of the Dsg3 gene (17). 
Immunoaffinity absorption experiments. For preabsorption of antibodies to Dsg 1 and 3, we used the baculoproteins Dsg1-Ig-His, Dsg3-His, and Dsg3-Ig-His produced in High Five cells grown in Sf-900 II SFM medium (Life Technologies Inc.). The baculoviruses provided by M. Amagai (Keio University, Japan) were amplified in Sf9 insect cell (Life Technologies Inc.), and the preabsorption experiments were performed exactly as described by Amagai et al. (23). Briefly, supernatant containing each recombinant protein was incubated with TALON metal affinity resin overnight at $4^{\circ} \mathrm{C}$ with gently rocking. After washing ten times with PBS containing $1 \mathrm{mM} \mathrm{CaCl}_{2}$, the TALON resins carrying immobilized baculoproteins were incubated with PV serum overnight. The resins with bound antibodies were washed 15 times with PBS, and the antibodies were eluted with an IgG gentle elution buffer (Pierce Chemical Co.). The eluants were cleared on DSalt Excellulose Plastic Desalting Column (Pierce Chemical Co.) and diluted in TBS containing $2 \%$ nonfat milk and $10 \mathrm{mM} \mathrm{CaCl}_{2}$.

For preabsorption of antibodies to the $\mathrm{Fc}$ portion of human IgG, we used the Ig-immunosorbent column containing Sepharose conjugated with the Fc fragment of human IgG (Bethyl Laboratories, Inc., Montgomery, Texas, USA), and the incubation and elution procedures already described here. The efficiency of adsorption of anti-Fc IgG antibodies on this column was tested by the ability of the preabsorbed FITC-conjugated goat anti-human Fc IgG antibody (Sigma Chemical Co.) to visualize PV IgG bound to monkey esophagus in a standard IIF assay. The amount of adsorbed anti$\mathrm{Fc}$ IgG antibodies was monitored by measuring the protein concentration in test IgG fraction before and after its absorption and comparing the differences with the protein concentration of the eluant.

Characterization by immunoblotting of antigenic reactivities of adsorbed PV IgGs. The PV IgGs eluted from Dsg 1 and Dsg 3 constructs and from the Ig-immunosorbent column were characterized by immunoblotting using as substrate protein the extracts of normal human keratinocytes and keratinocytes from Dsg 3-positive $\mathrm{BALB} / \mathrm{c}$ or Dsg 3-negative Dsg3 $3^{\text {mll }}$ mice that were resolved by SDS-PAGE and transferred to nitrocellulose membrane (Millipore Corp., Bedford, Massachusetts, USA), as detailed previously (24). The immunoblotting membranes were blocked with $5 \%$ nonfat milk in 20 $\mathrm{mM} \mathrm{Ca}^{2+}$-containing TBS ( $\mathrm{pH} 7.4$ ) for 1 hour at $37^{\circ} \mathrm{C}$. The blots were cut into 4 -mm-wide vertical strips, and each strip was exposed overnight at $4^{\circ} \mathrm{C}$ to an affinitypurified PV IgG diluted in TBS containing $1 \%$ normal goat serum, $3 \%$ nonfat milk, and $0.05 \%$ Tween 20 (Sigma Chemical Co.). Binding of primary antibody was visualized using horseradish peroxidase (HRP) conjugated goat anti-human IgG (Pierce Chemical Co.) with an HRP color developer (Bio-Rad Laboratories Inc., Hercules, California, USA). The specificity of binding was determined in negative control experiments, in which the primary antibody was omitted.
In a separate set of immunoblotting experiments, we examined antigenic reactivities of PV IgGs eluted from distinct keratinocyte protein bands, in accordance with the procedure for immunoaffinity antibody purification (43). Briefly, approximately 3-mm-wide horizontal strips carrying a keratinocyte protein with a specific $\mathrm{M}_{\mathrm{r}} \pm 3 \mathrm{kDa}$ were cut out from the immunoblotting membrane and incubated overnight with PV IgG serum fraction diluted $1: 5$ in TBS containing $20 \mathrm{mM}$ $\mathrm{CaCl}_{2}, 0.05 \%$ Tween 20 (Sigma Chemical Co.) and 1\% nonfat milk to allow antibody binding. The strips were then washed thoroughly, and the IgGs were eluted by a 3-minute incubation at $37^{\circ} \mathrm{C}$ in a solution containing $500 \mu \mathrm{L}$ of $20 \mathrm{mM}$ sodium citrate, $1 \%$ milk, and $0.05 \%$ Tween 20 ( $\mathrm{pH} 3.2$ ), and immediately neutralized by adjusting the $\mathrm{pH}$ to 7.4 with the $2 \mathrm{M}$ Tris base.

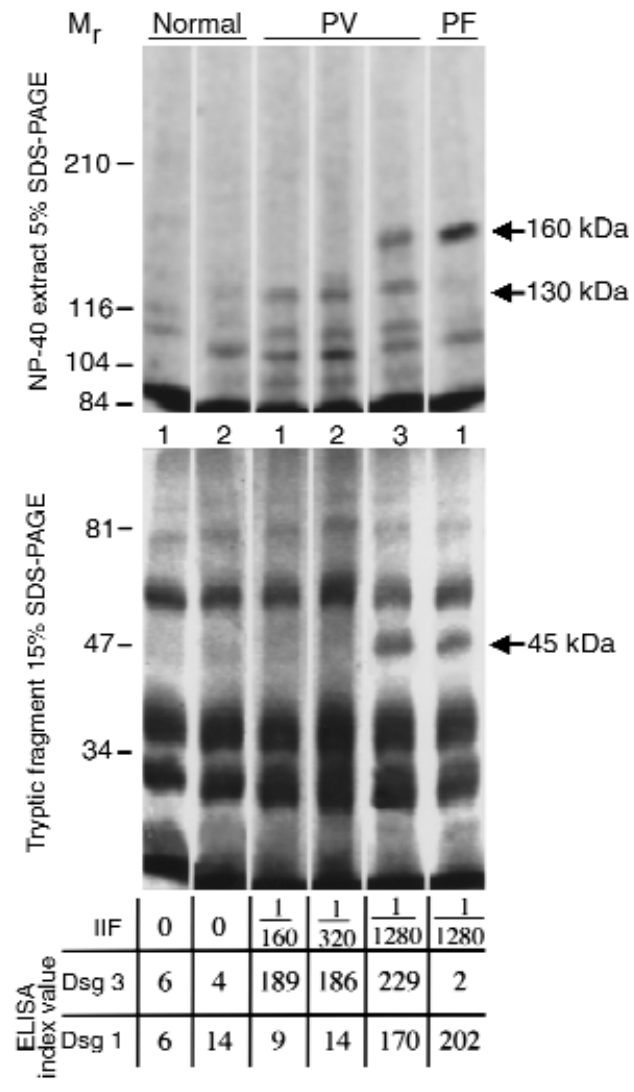

Figure 1

Characterization of PV and control sera. To identify the profiles of anti-keratinocyte antibodies, whole-cell (top) or $0.25 \%$ trypsindigested (bottom) protein extracts of $\left[{ }^{35} \mathrm{~S}\right]$ methionine-labeled human keratinocytes were immunoprecipitated with three different PV sera, one PF serum, and two sera from healthy volunteers, as detailed in Methods. The immune complexes were resolved on $5 \%$ (top) or $15 \%$ (bottom) SDS-PAGE, and the radiolabeled antigens visualized using the Storm system's phosphor-imager feature. The positions of the relative molecular mass markers in $\mathrm{kDa}$ are shown on the left. The titer of intercellular antibodies, determined by IIF on monkey esophagus, and the ELISA scores (IV) are shown on the bottom. MW, molecular weight. 


\section{Figure 2}

Induction of pemphigus in neonatal mice lacking Dsg 3 by passive transfer of IgGs from sera of PV patients that lack Dsg 1 antibody. Neonatal knockout Dsg3null mice homozygous for a targeted mutation of the Dsg3 gene (a-d) and "balding" Dsg3 $3^{\text {bal }} / D$ sg $3^{\text {bal }}$ mice homozygous for a spontaneous null mutation in the Dsg3 gene (e-h) were injected intraperitoneally with $20 \mathrm{mg} / \mathrm{g}$ body weight of $\mathrm{IgGs}$ from the PV1 serum that lacked Dsg 1 antibody. Approximately 18-24 hours after injection, large, flaccid blisters filled with serous fluid were seen on the skin of both $D s g 3^{\text {null }}(\mathbf{a})$ and $D s g 3^{\text {bal }} / D s g 3^{\text {bal }}$ (e) mice. At this time, the Nikolsky sign could be elicited on the skin of Dsg3null (b) and $D s g 3^{\text {bal }} / D$ sg3 $3^{\text {bal }}$ (f) mice by mechanical extension of a large erosion after spontaneous rupture of the blister. The blisters developed due to intraepidermal separation showing suprabasilar acantholysis and prominent tombstone appearance of the basal cell layer (c and $\mathbf{g}$; hematoxylin and eosin [H\&E]). DIF with FITC-conjugated anti-human IgG antibody revealed intercellular staining of epidermis due to deposition of injected PV IgGs ( $\mathbf{d}$ and $\mathbf{h}$ ). All neonates of the progeny from mating of homozygous Dsg3null mice showed the PCR product of 280 $\mathrm{bp}$, representing the sequence of the neomycin resistance gene used for the targeted disruption of the Dsg3 gene (17), and no 500-bp product, representing normal $D s g 3$ gene amplified from DNA extracted from a normal, Dsg 3-positive mouse (positive control). Likewise, all pups in the progeny from mating homozygous $D s g 3^{\text {bal }} / D s g 3^{\text {bal }}$ mice lacked Dsg 3, as illustrated by finding a nonfunctional homozygous mutational insertion, 2275ins T, upon direct nucleotide sequencing of the PCR product representing a portion of exon 14 of the mouse Dsg3 gene (data not shown). Scale bars $=50 \mu \mathrm{m}$.

\section{Results}

Characterization of Dsg 1 and Dsg 3 antibody profiles of $P V$ and $P F$ sera. The profile of anti-keratinocyte antibodies present in the sera of patients with PV was characterized by ESIA, using radiolabeled, naturally folded Dsg 1 and Dsg 3 , and ELISA, using recombinant proteins representing the extracellular domains of Dsg 1 and Dsg 3 (Figure 1). By both ESIA and ELISA, all PV sera, but not normal human or PF sera, contained autoantibody to the 130$\mathrm{kDa}$ Dsg 3. In ESIA, the PV1 and PV2 sera did not precipitate the $160-\mathrm{kDa}$ Dsg 1 nor its 45-kDa tryptic fragment (Figure 1), which constitutes the major antigenic region for anti-Dsg $1 \mathrm{PF}$ autoantibody and has been shown to be a very sensitive and specific probe for the anti-Dsg 1 antibody developed by patients with PV (31). Both PV1 and PV2 sera were also found negative for Dsg 1 antibody in ELISA assays (Figure 1). The commercial Dsg 1 ELISA kit used in our laboratory contained recombinant Dsg 1 developed by Amagai et al. (37). These negative results were confirmed in ELISA experiments performed in Diaz's laboratory (data not shown), using recombinant Dsg 1 developed by Ding et al. (44).

To eliminate the possibility that the autoantibodies to the conformational epitope of Dsg 1 remained undetectable in ESIA and ELISA due to limitations of these assays, we included PV3 serum and the PF serum as positive controls. These sera reacted with the $160-\mathrm{kDa}$ Dsg 1 that was present in the keratinocyte protein solution used in ESIA (Figure 1). These two positive control sera also immunoprecipitated the $45-\mathrm{kDa}$ fragment of Dsg 1 in ESIA and showed high titer of anti-Dsg 1 antibodies in ELISA (Figure 1).

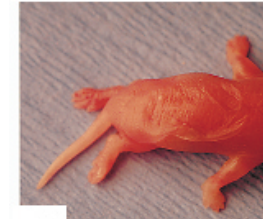

a
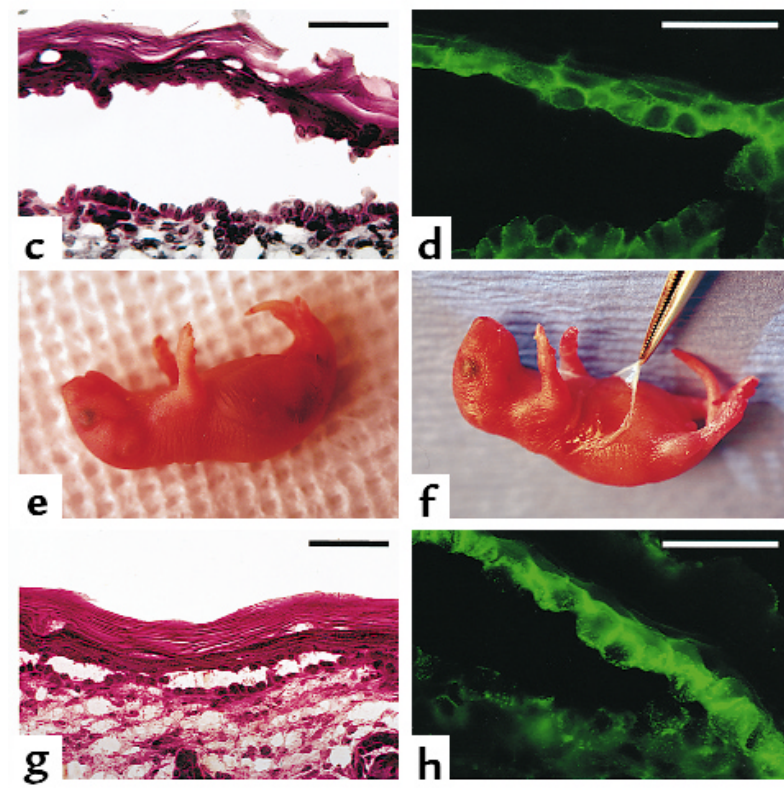

As negative controls, we used the sera from two healthy subjects without history of any blistering skin condition. These sera immunoprecipitated none of 130 - or 160 - or $45-\mathrm{kDa}$ keratinocyte polypeptides in ESIA and were negative for Dsg 1 and Dsg 3 antibodies in ELISA (Figure 1).

Thus, the four different approaches to detect Dsg 1 antibody in PV1 and PV2 sera produced negative results.

Is anti-Dsg 3 antibody the sole mediator of PV lesions? Mice lacking Dsg 3 do not spontaneously develop gross skin blisters $(1,16,17)$. If Dsg 3 is indeed essential for normal keratinocyte cell-to-cell adhesion in normal epidermis, the lack of skin lesions in Dsg3 $3^{\text {null }}$ and $D s g 3^{\text {bal }} / \mathrm{Dsg} 3^{\text {bal }}$ mice may be explained by a compensation mechanism in which upregulation of other adhesion molecules occurs. Therefore, these animals provide a unique Dsg 3-free system for probing PV sera for the presence of non-Dsg 3 autoantibodies targeting the molecules that mediate and regulate keratinocyte cellto-cell adhesion in the epidermis $(1,32)$. To determine whether non-Dsg 1/non-Dsg 3 PV antibodies are sufficient at causing skin blisters, we selected the two PV sera (PV1 and PV2) that did not contain Dsg 1 antibody, isolated IgG fractions and injected them intraperitoneally through a 30-gauge needle at a dose of $20 \mathrm{mg} / 1$ g body weight into 10 - to 12 -hour-old offsprings bred from homozygous female and male Dsg $3^{\text {null }}$ mice, as well as litters resulting from breeding pairs of homozygous $\mathrm{Dsg}^{\mathrm{bal}} / \mathrm{Dsg} 3^{\text {bal }}$ mice. Control littermates received the same doses of IgG isolated from pooled normal human serum (control). All neonates injected with PV IgGs (Figure $2 ; n=16)$, but not with normal human $\operatorname{IgG}(n=$ 


\section{Figure 3}

Characterization of acantholytic activities of pemphigus sera with different combinations of Dsg 1 and Dsg 3 antibodies in skin organ culture. The anti-keratinocyte antibody profiles of two Dsg 3 antibody-positive PV sera, one with (PV3) and one without (PV2) Dsg 1 antibody, Dsg 1 antibody-positive PF serum, and normal human serum (N2) were characterized by ESIA using 7.5\% SDS-PAGE (IP), and tested in fresh cultures of normal human skin as detailed in Methods. The morphological changes and antibody binding were examined by light microscopy (H\&E) and DIF, respectively. The PV2 serum that contained Dsg 3 antibody but no Dsg 1 antibody and the PV3 serum that contained both Dsg 1 and Dsg 3 antibodies produced identical changes: 36 hours after addition of each serum, deep suprabasilar, but not superficial, acantholysis and intercellular antibody binding throughout the entire epidermis could be seen in these skin specimens. In marked contrast, the PF serum had induced by this time point distinct subcorneal acantholysis accompanied by intercellular antibody binding throughout the entire epidermis. As can be seen in the left upper corner of the biopsy stained with H\&E, the split occurred within the granular cell layer. No alterations of the integrity of the epidermis or epidermal deposits of IgGs could be found in the cultures exposed for 96 hours to a healthy subject's serum. In the column labeled IP, the relative molecular mass of the bands precipitated by each pemphigus serum is designated with arrows, and the positions of standard relative molecular mass markers are shown in the lowermost row. Scale bars $=50 \mu \mathrm{m}$.

12; data not shown), developed extensive, flaccid skin blisters approximately 18-24 hours after a single injection. The blisters resulted from suprabasilar acantholysis associated with binding of non-Dsg 1/non-Dsg 3 antibodies to the cell surface of murine epidermal keratinocytes (Figure 2). Identical clinical and microscopic features were produced in normal BALB/c mice by PV1 $(n=4)$ or PV2 $(n=6)$ IgGs (data not shown).

To eliminate the possibility that pups with blisters developed a revertant mutation that restored expression of the Dsg3 gene, the expected genotypes of all pups was confirmed at the end of each experiment (data not shown).

Thus, PV-like skin lesions in neonatal mice can be produced by $\mathrm{PV}$ autoantibodies to keratinocyte proteins other than Dsg 1 and Dsg 3.

Does Dsg 1 antibody contribute to acantholytic activity of $P V$ serum? The results discussed here indicated that anti-Dsg 3 antibody may not be critical for skin blister formation in patients with $\mathrm{PV}$, in agreement with the conclusion of Mahoney et al. (32) that anti-Dsg 3 alone is not sufficient at causing skin blistering. However, the possibility that in our passive transfer experiments the skin lesions were caused by a "hidden" anti-Dsg 1 antibody could not be excluded because, theoretically, this antibody might not recognize the conformational epitopes of any Dsg 1 molecules present in either antigenic substrate used by four different antibody detection assays (Figure 1). Although patients with PV never develop the superficial epidermal acantholysis seen with anti-Dsg 1 (44), this antibody still may be pathogenic. If so, the lack of PF-like pathology in patients with PV might be explained by prevention of anti-Dsg 1 antibody entry of the granular cell

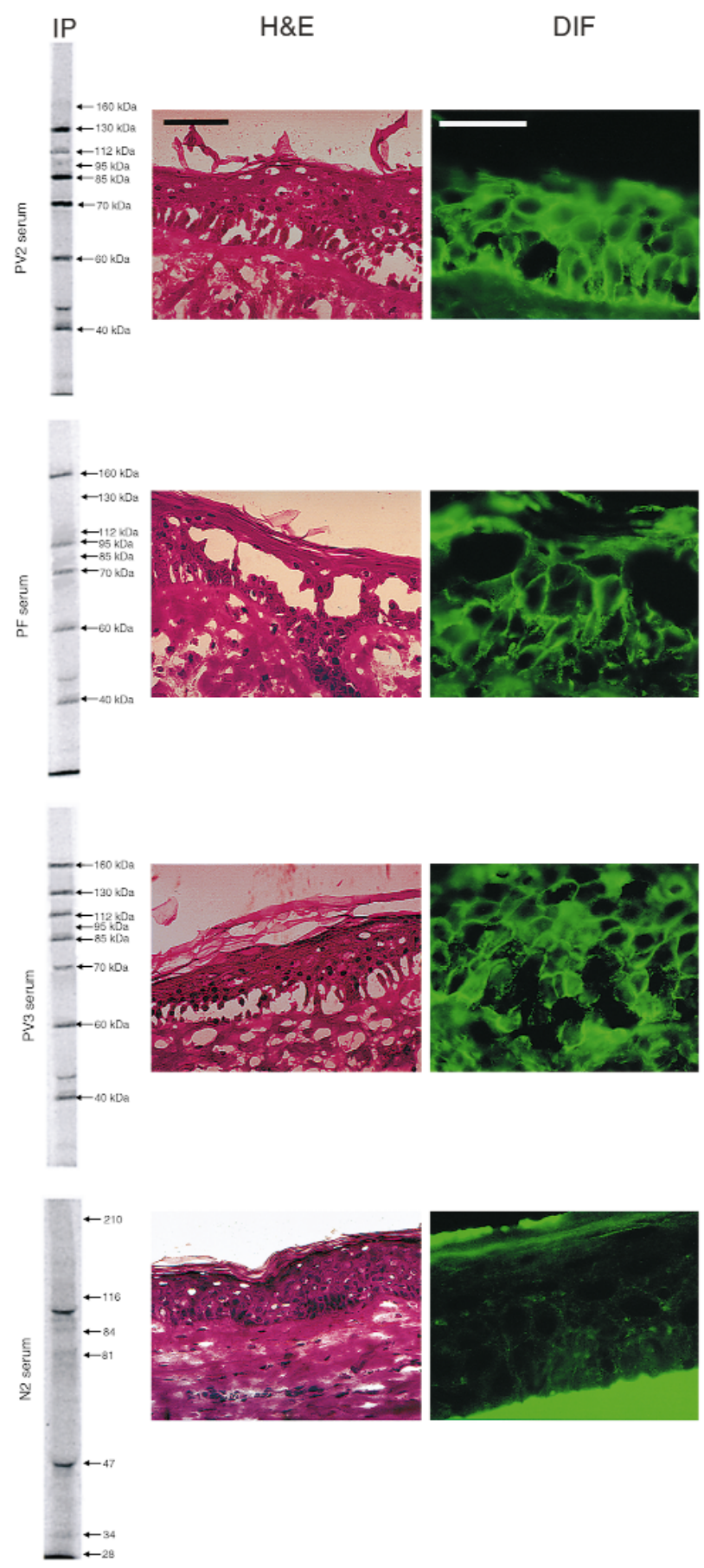

layer by the deep suprabasilar split in the epidermis of these patients. We tested this hypothetical mechanism using an in vitro model of $\mathrm{PV}$ in which all epidermal layers are equally accessible to antibodies. The normal human skin specimens were bathed in the medium containing pemphigus antibodies for different time periods, and penetration of the antibodies throughout all epidermal layers with their subsequent deposition on the cell membrane of keratinocytes was confirmed by DIF. We tested (a) PV serum containing anti-Dsg 3 antibody without anti-Dsg 1 antibody (PV2 serum); (b) PV serum 
with both anti-Dsg 1 and anti-Dsg 3 antibodies (PV3 serum); (c) PF serum featuring anti-Dsg 1 antibody without anti-Dsg 3 antibody; and (d) a healthy volunteer serum (N2, i.e., normal serum 2 in Figure 1). The first signs of acantholysis in skin organ cultures treated with pemphigus sera could be observed as early as 24 hours of incubation (data not shown). Extensive acantholysis with wide intraepidermal clefting was observed by the end of the second day of incubation. After the 4th day, nonspecific changes, such as keratinocyte apoptosis and vacuolar and ballooning alterations, could be observed in the epidermis of all skin organ cultures. Therefore, all experiments were terminated at 72 hours of incubation, and the changes produced by test sera by that time point were compared.

As seen in Figure 3, the PV2 serum containing the 130-kDa Dsg 3 antibody caused deep suprabasilar acantholysis. The basal cells remained attached to the basement membrane, rendering the tombstone appearance, which is the histopathological hallmark of PV (45). The PF serum with the $160-\mathrm{kDa}$ Dsg 1 antibody produced acantholysis in the superficial layer of the epidermis (Figure 3). The split occurred within the granular cell layer. In marked contrast, the PV3 serum that, in addition to anti-Dsg 3 antibody, also contained anti-Dsg 1 antibody caused only suprabasilar acantholysis, but no superficial split that would be expected if anti-Dsg $1 \mathrm{PV}$ antibodies were pathogenic (Figure 3). When these skin organ cultures were examined by DIF, the IgGs present in all three test pemphigus sera stained the entire epidermis, including the granular cell layer, in a similar intercellular, pemphigus-like pattern, which is consistent with the general observations that the DIF patterns of PV and PF sera are indistinguishable in most cases (46).

To distinguish pemphigus antibody-induced effects from nonspecific or degenerative changes in the cultured epidermis, parallel skin samples from the same skin donor were incubated with normal human sera. The bottom row of Figure 3 shows that no alterations of the integrity of the epidermis or any deposits of $\operatorname{IgG}$ could be detected in the cultures incubated with the N2 serum for 4 days.

Thus, anti-Dsg 1 antibody present in PV serum does not exhibit acantholytic activity at its normal serum concentration, in agreement with the findings of Ding et al. (44).

Can anti-Dsg 1 antibody cause PV-like skin lesions in Dsg $3^{\text {null }}$ mice? A role for anti-Dsg 1 antibody in $\mathrm{PV}$ was proposed in the "desmoglein compensation" hypothesis (47), which is based on a report that both PV and PF IgGs produce identical suprabasilar split in Dsg $3^{\text {null }}$ mice (32). The hypothesis attempts to reconcile the discrepancy between the known correlation of anti-Dsg 1 antibody with subcorneal epidermal split of PF and suprabasilar location of acantholysis in PV. However, insufficient thickness of murine epidermis may have hampered localization of the split. Therefore, in this study we compared the epidermal morphology at different anatomical regions of wild-type and $D s g 3^{\text {zull }}$ mice.
The IgG fractions of PF sera and PV3 sera, both of which contained anti-Dsg 1 antibody (Figure 1), were injected intraperitoneally at a dose of $10 \mathrm{mg} / \mathrm{g}$ body weight into 10 - to 12 -hour-old $D s g 3^{\text {mull }}$ mice (16 pups received PF IgG; seven pups received PV3 IgG) or $\mathrm{BALB} / \mathrm{c}$ mice (nine pups received PF IgG; five pups received PV3 IgG), and skin samples were obtained 24 hour thereafter. Both strains of mice injected with PF IgG developed superficial skin peeling, or wrinkling, with a positive Nikolsky sign (Figure 4a). Light microscopic examination revealed superficial, or subcorneal, epidermal acantholysis, as in patients with PF (Figure $4 \mathrm{~b})$. However, in locations where the basal cell layer was the only nucleated cell layer of the epidermis (Figure 4, $\mathrm{b}$ and $\mathrm{c}$; arrows), the subcorneal split appeared as a suprabasilar split. The morphological pattern shown in Figure $4 \mathrm{~b}$ was seen in the specimens obtained from the head/neck and axillary areas, where the epidermis is relatively thick, whereas the pattern seen in Figure 4c could be observed in skin of the trunk and extremities, where epidermis is thinner. In marked contrast, all pups injected with PV3 IgGs (Figure 4d) showed clinical and morphological acantholysis that was indistinguishable from that seen in mice injected with the PV IgGs that did not contain anti-Dsg 1 antibody. The deep intraepidermal localization of the acantholytic cleft, which was obvious in the skin areas with thick epidermis (Figure 4d), confirmed that the split induced by PV IgGs in the abdominal skin of Dsg 3-deficient mice, where the epidermis is thin (Figure 2, c and g), was also suprabasilar rather then subcorneal. The subcorneal split was never found in skin specimens from mice injected with the PV IgGs that were either positive or negative for anti-Dsg 1 antibody.

Thus, upon passive transfer to neonatal $D s g 3^{\text {null }}$ mice, PV or PF IgGs produce two distinct, PV-like or PF-like phenotypes, respectively, eliminating the possibility that gross skin blisters and deep suprabasilar acantholysis in Dsg 3-lacking mice injected with PV IgGs (Figure 2) were caused by any unidentified anti-Dsg 1 antibody. The PV-like skin lesions were therefore induced by non-Dsg 1/non-Dsg 3 antibodies.

Do Dsg 1 and Dsg 3 chimeric baculoproteins absorb similar disease-causing non-Dsg PV antibodies? These results provided evidence that non-Dsg 1/non-Dsg 3 antibodies can cause skin blisters in patients with PV. How then could Dsg 1 and Dsg 3 constructs absorb out all disease-causing PV antibodies in previous studies $(21,23$, $32,48)$ ? Because the antigenic profile of the eluted PV IgGs was not characterized in those studies, the issue of monospecificity of the recombinant Dsg proteins used in absorption experiments required examination. We therefore produced the recombinant baculoproteins using the baculoviruses provided by M. Amagai, repeated the absorption experiments exactly as described in the original studies $(21,23)$, and characterized the immunoreactivities of the eluted, diseasecausing PV IgG by immunoblotting using different keratinocyte substrates. Preliminary results indicated 


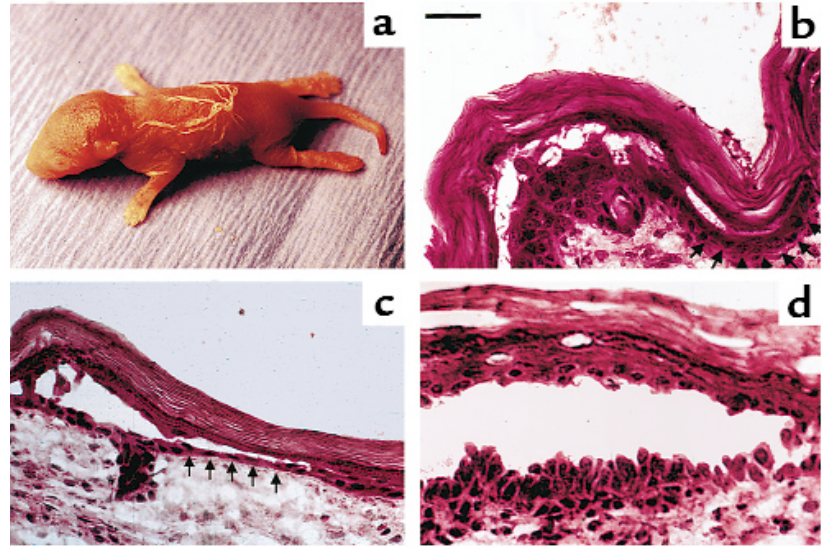

\section{Figure 4}

Passive transfer of PV and PF IgGs to neonatal Dsg3null mouse produce two distinct phenotypes in the epidermis. The PF IgG that immunorecognized Dsg 1 and did not cross-react with Dsg 3 and the PV3 IgG that contained antibodies to both Dsg 1 and Dsg 3 were injected at a dose of $10 \mathrm{mg} / \mathrm{g}$ body weight into 10- to 12-hour-old neonates of the litter that resulted from breeding homozygous female and male Dsg3 $3^{\text {null }}$ mice. Wrinkling of the skin of a Dsg3 $3^{\text {null }}$ mouse was noticed approximately 20 hours after a single injection of PF IgG (a). Approximately 22 hours after injection, the pups were euthanized, and two skin specimens, one from the neck/head area and one from abdominal skin, were obtained, stained with $\mathrm{H} \& \mathrm{E}$, and examined by light microscopy. In both anatomical regions, the epidermal split induced by PF IgGs is subcorneal, rather than suprabasilar (b and $\mathbf{c}$ ). The subcorneal location of the split can be easily misinterpreted as being suprabasilar in locations where the basal cell layer is the only nucleated cell layer of the epidermis (arrows). The accurate conclusions, however, should be drawn based on the phenotype found in the skin regions where the epidermis is thick, such as in the most parts of the specimen from the head/neck area shown in the $\mathbf{b}$. In this skin region, the suprabasilar split caused by PV3 IgG is seen in the deep epidermis (d). The Dsg 3 $3^{-/}$genotype of these mice was confirmed by PCR amplification of the sequences of genomic DNA extracted from the tail (1). Scale bar $=50 \mu \mathrm{m}$.

that the antigenic profiles of PV IgG eluted from rDsg3-His and rDsg3-Ig-His are different, suggesting that addition of the Fc IgG portion to the extracellular portion of Dsg 3 created a new epitope recognized by pathogenic non-Dsg 3 PV IgG (24). Alternatively or additionally, rDsg3-Ig-His might absorb anti-Fc IgG antibody (also known as rheumatoid factor). To test this hypothesis, we in this study compared the antigenic profiles of PV IgGs eluted from the rDsg3-His versus $r D s g 3-I g-H i s$ versus $r D s g 1-I g-H i s$ versus Fc IgG columns. The authenticity of the Dsg3-His, Dsg3-Ig-His and Dsg1-Ig-His baculoviruses was verified by PCR (Figure $5 \mathrm{a}$ ), and the reactivities of produced baculoproteins with PV antibodies were confirmed by immunoblotting (Figure 5b). The efficiency of the Fc IgG column in absorbing ant-Fc IgG antibodies was demonstrated by the ability of the FITC-conjugated goat anti-human Fc IgG antibody that was first preabsorbed on and then eluted from the column to visualize PV IgG bound to the monkey esophagus substrate in a standard IIF assay (data not shown).
The antigenic profile of PV IgGs adsorbed on each recombinant protein was characterized by immunoblotting (Figure 6). The PV3 IgG eluted from rDsg3-His recognized mainly the $130-\mathrm{kDa}$ human keratinocyte protein but also stained weakly a few bands with lower relative molecular mass. The PV3 IgG eluted from rDsg3-Ig-His reacted with a mixture of protein bands, including a $130-\mathrm{kDa}$ polypeptide present in $D s g 3^{\text {null }}$ keratinocytes (Figure 6). Most of protein bands visualized by PV3 IgG eluted from rDsg1-Ig-His showed molecular weights that were very similar to those visualized by PV3 IgG eluted from rDsg3-Ig-His (Figure 6). The PV3 IgG eluted from the Fc IgG column ( $\sim 12 \mathrm{mg}$ total) did not recognize murine epidermal proteins in either Western blotting (Figure 6) or IIF (data not shown) assays. However, given that PV3 serum contained a rheumatoid factor $(62 \mathrm{IU} / \mathrm{ml})$, to rule out even a remote possibility that this antibody could induce skin changes in vivo, we tested PV3 IgG eluted from the Fc IgG column in passive transfer experiments with Dsg 3-deficient neonatal mice. We could not find any gross or microscopic skin changes, elicit Nikolsky sign, or detect any specific antibody binding to the epidermis in any of the four $D s g 3^{b a l} / \mathrm{Dsg} 3^{\text {bal }}$ mice that were injected subcutaneously with $1.5 \mathrm{mg} / \mathrm{g}$ body weight of affinity-purified anti-Fc IgG antibody and observed for at least 24 hours after injection after which the animals were sacrificed. These results showed that the anti-Fc IgG antibody present in the PV3 IgG fraction does not cross react with keratinocyte proteins by immunoblotting and IIF, does not bind to the epidermis of Dsg 3 deficient mice in vivo and does not cause any skin changes in passive transfer experiments. This antibody, therefore, could not contribute to the staining of murine epidermal proteins and intraepidermal blisters produced by PV3 IgG eluted from the rDsg3-Ig-His construct.

Most likely, addition of the Fc IgG1 sequence to the Dsg 1 and Dsg 3 extracellular epitopes rendered novel secondary or tertiary structures to these adhesion molecules. If the newly formed antigenic epitope represented conformational epitope of Dsg 3, then multiple bands visualized by PV3 IgGs eluted from rDsg1-Ig-His or rDsg3-Ig-His would result from random cross-reactivities of anti-Dsg 3 antibodies with other keratinocyte proteins. If these cross reacting anti-Dsg 3 autoantibodies were polyclonal, then antiDsg 3 IgG eluted from any single band should have been able to produce the same or very similar multipleband staining pattern as the whole PV3 IgG fraction did. If the autoantibodies were monoclonal, then at least two bands, the $130-\mathrm{kDa}$ band and the one from which that specific IgG was eluted, should have been visualized upon re-staining.

To examine these intriguing possibilities, we characterized the antigenic profile of PV3 IgG eluted from a horizontal $190-\mathrm{kDa}$ band strip cut from a wide immunoblotting membrane. We selected this band based on the following two main reasons: (a) it had 
the highest relative molecular mass compared with other bands visualized by PV3 IgGs eluted from rDsg3-Ig-His, which excluded a possibility that it represented a degradation product of any desmosomal cadherin; and (b) it was located at the edge of the antigenic "ladder" visualized on the immunoblotting membrane, which diminished to the minimum a chance that the horizontal strip cut at this area of the membrane could carry any other pemphigus antigens. The experiments showed that only $190-\mathrm{kDa}$ band, but not 130 - or $160-\mathrm{kDa}$ band or any other band with a low relative molecular mass, could be stained with the antibody eluted from $190-\mathrm{kDa}$ area of the immunoblotting membrane (Figure 6). These results indicate that the disease-causing PV IgGs absorbed with rDsg3-Ig-His represent a mixture of autoantibodies to an array of new keratinocyte self-antigens, including yet unidentified non-Dsg 3 polypeptides with apparent $\mathrm{M}_{\mathrm{r}}$ of 190 and $130 \mathrm{kDa}$. These results also indicate that the protein bands with lower relative molecular mass recognized by PV IgG eluted from the chimeric baculoproteins do not represent degradation products of the $190-\mathrm{kDa}$ pemphigus antigen.

Thus, Dsg 3 chimeric baculoprotein absorbs out all disease-causing PV antibodies nonspecifically, perhaps due to creation of new secondary or tertiary epitopes as a result of unique folding of the chimeric baculoprotein composed of two unrelated polypeptide sequences.

\section{Discussion}

In this study, we demonstrate for the first time that, in addition to Dsg 1 and Dsg 3, other keratinocyte proteins can be targeted by disease-causing PV antibodies and that neither anti-Dsg 1 nor anti-Dsg 3 antibody is critical for induction of PV-like skin blisters. These results were obtained in in vitro and in vivo models of pemphigus, using a novel, high sensitivity-and-specificity metabolic uptake assay, ESIA, in combination with the ELISA that uses supposedly pathogenic recombinant extracellular epitopes of Dsg 1 and Dsg 3. The discrepancy of these results with the postulated exclusive roles of anti-Dsg 1 and anti-Dsg 3 antibodies in mediating clinical and microscopic signs of pemphigus can be explained by our findings that both rDsg1-Ig-His and rDsg3-Ig-His chimeric baculoproteins, in addition to absorbing the purportedly unique autoantibodies against the adhesion molecules Dsg 1 and Dsg 3, also absorb a heterogeneous group of autoantibodies targeting other keratinocytes proteins.

Blisters in pemphigus occur by intraepidermal clefting that results from breakdown of cell-to-cell adhesion. Intercellular spaces enlarge; desmosomes decrease in number and eventually disappear; and the cells round up and detach from one another without cell death (acantholysis) $(45,49-51)$. Blisters in pemphigus are associated with the binding of IgG autoantibodies to the keratinocyte cell surface (52). The pathophysiological importance of anti-Dsg autoimmunity in pemphigus has been suggested (8-10) by the results of experiments showing the ability of recombinant Dsg 1 and Dsg 3 constructs to absorb disease-causing antibodies from $\mathrm{PF}$ and PV sera, respectively (21-23). Validity of this theory was diminished when marked epidermal acantholysis and extensive skin blistering was induced in otherwise normal Dsg $3^{\text {null }}$ neonatal mice by passive transfer of PV IgGs (1). As was determined by immunoblotting and standard immunoprecipitation techniques, the PV IgG fractions injected into Dsg 3-deficient mice did not contain anti-Dsg 1 antibody (1). However, it has been recently reported that absorption of PV sera with recombinant Dsg 1 could eliminate all disease-causing activity in passive transfer experiments with $D s g 3^{\text {null }}$ mice, suggesting that anti-Dsg 1 antibody is responsible for the PV-like phenotype in these pups (32). Therefore, in our previous study (1) the disease-causing anti-Dsg 1 antibodies might have been undetectable due to destruction of con-

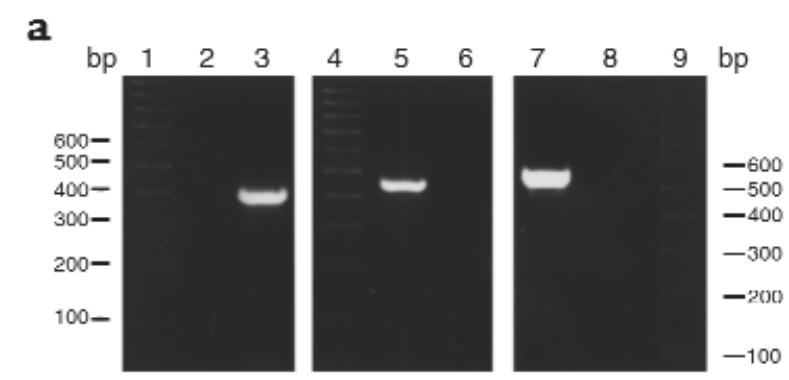

b

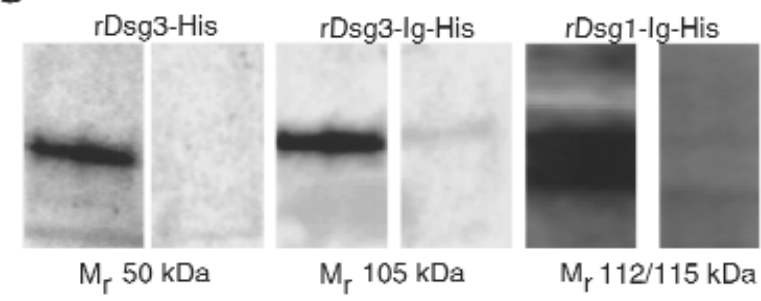

\section{Figure 5}

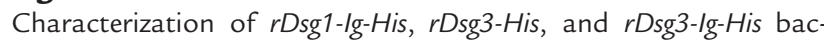
uloviruses and baculoproteins. (a) PCR amplifications of DNA isolated from High Five insect cells infected with the $r D s g 3-H i s$ (lanes 2 and 3), rDsg3-Ig-His (lanes 5 and 6), or rDsg1-Ig-His (lanes 7 and 8). Lanes 1, 4, and 9 show positions of 100 bp DNA markers. The 380-bp Dsg3His product (lane 3 ) was amplified using a pair of forward and reverse primers matching the sequences of the Dsg3 gene. In the negative control experiment (lane 2), the same template and a sense primer were used, but the reverse primer matched the sequence of the Fc portion of human IgG. The latter set of primers amplified the 420-bp product from the DNA extracted from the insect cells infected with the $r D s g 3$ $\mathrm{I}$-His baculovirus (lane 5), but not from noninfected cells (lane 6). Similarly, rDsg1-Ig-His was amplified using the forward Dsg 1 primer and the reverse Fc IgG1 primer, giving a 530-bp PCR product (lane 7), whereas no product was obtained in the control experiment using DNA from noninfected cells (lane 8 ). (b) The reactivity of PV3 IgGs with recombinant Dsg 1 and Dsg 3 baculoproteins. Western blots of the SDS-PAGE-resolved baculoproteins rDsg3-His (left), rDsg3-Ig-His (middle), and rDsg1-Ig-His (right) purified and concentrated on the TALON affinity metal resin and probed with PV3 serum, as detailed in Methods. Each visualized protein migrated with the expected relative molecular mass (left lane of each panel). The right lane of each panel shows absence of staining due to omission of the primary antibody. 
formational epitope of Dsg 1 in the course of immunoblotting and/or relatively low sensitivity of the standard immunoprecipitation assay used.

In this study, the anti-keratinocyte antibodies developed by patients with pemphigus were characterized using naturally folded keratinocyte proteins as antigens. We used the enhanced sensitivity metabolic labeling assay, ESIA, in which the sensitivity and resolution is enhanced by the ability of the Storm system's phosphor-imager feature to capture the image from both strong and weak signals in a single exposure $(53,54)$. To increase the sensitivity of our detection technique even further, we probed the sera with a $45-\mathrm{kDa}$ immunoreactive fragment of Dsg 1 purified by Con A affinity chromatography (36). The $45-\mathrm{kDa}$ polypeptide is a fragment of Dsg 1, as can be judged from the sequencing data reported by Abreu-Velez et al. (55), and

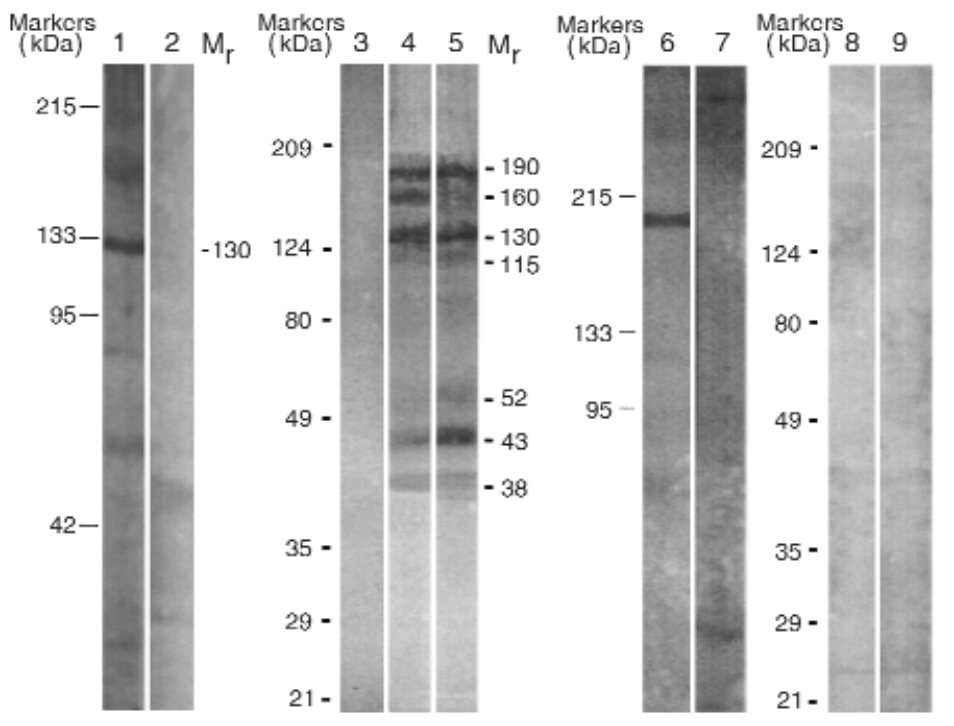

Figure 6

The profiles of the PV IgGs absorbed by recombinant Dsg 1 and Dsg 3 baculoproteins. Western blots of protein extracts of normal human keratinocytes resolved by $7.5 \%$ SDS-PAGE and stained with PV3 IgG affinity-purified on rDsg3His (lane 1), and that of Dsg $3^{\text {null }}$ keratinocytes stained with PV3 IgG affinity purified on rDsg3-Ig-His (lane 5), rDsg1-Ig-His (lane 4) or on the Fc IgG column (lane 9 ). Binding of PV3 IgGs to the immunoblotting membranes was visualized using secondary, HRP-conjugated goat anti-human IgG antibodies. Lane 6 shows a single protein band with apparent $\mathrm{M}_{\mathrm{r}}$ of $190 \mathrm{kDa}$ among SDS-PAGE-resolved Dsg 3 -positive keratinocyte proteins from BALB/c mouse. This band was visualized by the PV3 IgG that was eluted from the 190-kDa area of the Western blot of Dsg3null keratinocyte proteins stained with the PV3 IgG adsorbed on rDsg3-Ig-His. Note: Only a 190-kDa but not 130- or 160-kDa band or any other keratinocyte protein was visualized, indicating that the antibody targeting the $190-\mathrm{kDa}$ protein is a unique one, as it does not recognize the 130-kDa Dsg 3 or 160-kDa Dsg 1. Lanes 2,3 , and 7 are the negative controls omitting primary antibody. The Dsg3null keratinocyte protein extract in lane 8 was blotted with normal human IgG-affinity purified on rDsg3-Ig-His. The lack of multiple bands in lane 8 as well as complete absence of specific staining in lanes 3 and 7 indicate that there were no nonspecific cross reactivities of human or goat IgGs with murine epidermal proteins. The positions of relative molecular mass markers run in parallel lanes of each blot are shown to the left of the respective blot. The apparent relative molecular mass of keratinocyte protein bands visualized due to PV antibody binding is shown to the right of lanes 2 and 5 in the columns designated $M_{r}$. is believed to be a very sensitive probe for anti-Dsg 1 series of ELISA experiments using as antigens the extrapathogenic anti-Dsg antibodies produced by patien with different forms of autoimmune pemphigus (23, (3), 44, 56). This combination of highly sensitive in acantholytic activities in vivo and in vitro. caused gross skin blisters with suprabasilar acantholyis and produced a fishnet-like, intercellular staining pattern of perilesional epidermis in two different mice lacking Dsg 3. By ESIA, in addition to the $130-\mathrm{kDa}$ Dsg 3 target that was absent in these mice, the non-Dsg 1 pathogenic PV IgGs uniquely recognized keratinocyte proteins of approximately 38, 43, 115, and 190 $\mathrm{kDa}$. The possibility that the anti-Dsg 3 antibody cross-reacted with Dsg 1 on the cell surfaces of murine keratinocytes, leading to acantholysis via this pathway, is unlikely because Dsg 3 antibody produced by patients with PV does not cross-react with Dsg $1(44,56)$. This was confirmed in this study by lack of protein bands with apparent $\mathrm{M}_{\mathrm{r}}$ of $160 \mathrm{kDa}$ in Western blots stained with the Dsg 1 antibody-positive PV3 IgG eluted from rDsg3-His or rDsg3-Ig-His. Furthermore, a semiquantitative IIF assay shows that the epidermis of Dsg $3^{\text {null }}$ mice immunoreacts with only $58 \%$ of the relative amounts of PV IgGs bound in the epidermis of the $D s g 3+/+$ BALB/C mice, defined as $100 \%$, indicating that anti-Dsg 3 antibody present in PV IgG fractions does not bind to the Dsg 3-negative keratinocytes (1). Indeed, commercially available antibody to Dsg 3 also does not stain the epidermis of Dsg $3^{\text {null }}$ and $D s g 3^{b a l} / D s g 3^{b a l}$ mice (1). Furthermore, the results of our organ culture experiments demonstrate that anti-Dsg 1 antibody present in PV sera is unable to induce superficial acantholysis characteristic of PF.

Thus, PV-like skin lesions in Dsg 3-deficient mice injected with PV IgG mice seemed to be induced through a pathophysiological mechanism exclusive of any Dsg 1 and Dsg 3 antibody-mediated pathways. However, the ultimate conclusion could not be made until after resolution of the controversy about microscopic localization of skin blisters in $D s g 3^{\text {null }}$ neonatal mice injected with anti-Dsg 1 antibody $(32,48)$.

To address a hypothetical possibility that in our passive transfer experiments (Figure 2) 
the skin blisters were caused by some hidden anti-Dsg 1 antibody, we investigated thoroughly the pathology of the skin of $D s g 3^{\text {null }}$ neonatal mice injected with the Dsg 1 antibody-containing PF IgG. We found the superficial intraepidermal split. However, the location of the split could be also called suprabasilar in anatomical regions where the basal cell layer was the only nucleated cell layer of the epidermis. Identical gross and microscopic changes were observed in wild-type Dsg 3-positive mice injected with PF IgGs. Therefore, as either Dsg3 $3^{\text {null }}$ or $D s g 3^{\text {bal }} / D s g 3^{\text {bal }}$ or wild-type mice injected with PV IgG never develop any evidence of PF-like subcorneal split, but always demonstrate deep, suprabasal acantholysis, it is extremely unlikely that the PV-like phenotype in Dsg 3-negative neonates injected with PV IgG was caused by some hidden anti-Dsg 1 antibody. The keratinocytes in Dsg 3-negative mice, however, may be more sensitive to non-Dsg antibodies than in wild-type mice.

Having established that non-Dsg 1/non-Dsg 3 PV IgGs are capable of inducing PV-like skin blisters, we inquired how could the recombinant Dsg 1 and Dsg 3 constructs that also carry Fc IgG1 portion absorb out all disease-causing antibodies from PV sera $(21-23,32)$ ? Furthermore, in our own experiments, absorption of PV sera with rDsg3-Ig-His eliminated the ability of IgGs purified from these sera to cause acantholysis in Dsg 3-negative Dsg $3^{\text {null }}$ mice, whereas the PV IgG eluted from rDsg3-IgHis induced skin blisters in these mice (24). Therefore, because the Dsg 3 antigen was not present in the epidermis of $D s g 3^{\text {null }}$ mice, the interpretations that rDsg3-Ig-His absorbs disease-causing PV IgGs due to a permissive conformation mimicking the authentic epitope, in contrast to rDsg3-His, which lacks this ability, and that its conformation is important in the pathogenesis of PV become untenable. To clarify the relevant mechanisms, we compared the antigenic profiles of PV antibodies absorbed by rDsg1-Ig-His and rDsg3-Ig-His. Both chimeric baculoproteins absorbed a series of autoantibodies, recognizing, in addition to the $160-\mathrm{kDa}$ Dsg 1 and $130-\mathrm{kDa}$ Dsg 3, respectively, keratinocyte proteins with apparent $\mathrm{M}_{\mathrm{r}}$ of $38,43,115$, and $190 \mathrm{kDa}$. These results strongly suggested that both chimeric baculoproteins absorb identical non-Dsg antibodies, and that addition of Fc portion of IgG1 to the extracellular epitopes of Dsg 1 and Dsg 3 accounts for similar antibody reactivities of both chimeras. Thus, the chimeric baculoproteins used in the past to remove disease-causing activity of PV and PF sera, which is the only evidence directly supporting the notion that anti-Dsg 1 and anti-Dsg 3 antibodies are pathogenic, actually absorbed out autoantibodies directed to multiple keratinocyte cell membrane proteins. Hence, although the conformational epitopes of these baculoproteins are indeed recognizable by disease-causing PV and PF antibodies, the autoantibodies are heterogeneous. These chimeras, therefore, may become a useful tool for elimination and further characterization of antibodies causing PV and PF.

Further investigation of PV and PF disease-causing antibodies may take advantage of recent discoveries of two new human keratinocyte molecules targeted by disease-causing PV IgGs, namely: (a) the $\alpha 9$ acetylcholine receptor with dual muscarinic-and-nicotinic pharmacology (24), and (b) pemphaxin, a novel annexin (also known as annexin 31 or ANXA9) that can act as an acetylcholine receptor (35). The pathophysiological importance of these new molecules in pemphigus is illustrated by the ability of rabbit monoepitopic anti- $\alpha 9$ antibody to cause pemphigus-like acantholysis in keratinocyte monolayers, and by elimination of the diseasecausing activity of PV IgGs by preabsorption with recombinant pemphaxin. These observations are in keeping with earlier findings showing that $85 \%$ of patients with PV and of those with PF develop autoantibodies to keratinocyte acetylcholine receptors (1), and a large body of evidence demonstrating that pemphigus antibody binding to the keratinocyte cell membrane evokes a cascade of intracellular biochemical reactions (reviewed in refs. $1,57)$, including those that directly alter expression and function of Dsg $3(58,59)$ and other adhesion molecules, such as vinculin and connexin 43 (60).

Acetylcholine receptors and annexins are functionally coupled to regulation of intracellular $\mathrm{Ca}^{2+}$ and control cell adhesion and motility (reviewed in refs. 61, 62). Recent studies of molecular mechanisms of epithelial adhesion have revealed that $\mathrm{Ca}^{2+}$-mediated actin-polymerization is the major driving force for keratinocyte cell-to-cell attachment and that desmosome assembly is a passive process that occurs once the stable cell-cell contact has been made (63). It is therefore worth noting that acantholysis and a loss of skin adhesion in HaileyHailey disease and in Darier disease result from defects in genes encoding an ATP-powered calcium pump that sequesters calcium in the Golgi apparatus (64) and a sarco/endoplasmic reticulum-Golgi calcium pump (65), respectively. Altogether, these findings elucidate, on the one hand, the morphological similarities between keratinocyte acantholysis induced by either cholinolytic drugs or pemphigus antibody, and, on the other hand, the ability of the cholinomimetic drugs to abolish PV IgG-induced acantholysis (reviewed in ref. 66).

In summary, the results of this comprehensive study reveal, for the first time to our knowledge, the following facts which will be critical in formulating further conclusions about the pathophysiology of PV: (a) PVlike skin lesions can be induced without participation of either anti-Dsg 1 or anti-Dsg 3 antibodies. (b) PV and PF IgGs produce different disease phenotypes in Dsg $3^{\text {null }}$ mice. (c) Absorption of similar non-Dsg antibodies with rDsg1-Ig-His and rDsg3-Ig-His reconciles the controversy about the role of anti-Dsg 1 and antiDsg 3 antibodies in pemphigus.

We conclude that acantholysis in PV is mediated by an active process triggered by a yet incompletely understood pathogenic mechanism, including autoantibodies to different types of keratinocyte cell membrane proteins. Our "multiple hit" hypothesis assimilates diverse postulates on the roles of different autoantibodies in pemphigus (66). We propose that antibody 
binding to multiple cell-surface target antigens induce acantholysis. The severity of disease and the specific clinical presentation in each particular patient depend on the contributions and relative concentrations of multiple anti-keratinocyte autoantibodies. Future studies, therefore, should be directed toward identification of the keratinocyte membrane proteins targeted by disease-causing antibodies in each patient with PV or PF, and elucidation of the immunopharmacological actions of novel disease-causing pemphigus IgGs.

\section{Acknowledgments}

We thank Peter M. Yau from the Department of Biochemistry, University of California Davis Medical School, for help with analysis of the radioactivity of immunoprecipitation gels on the Storm system. The colony of mice with targeted disruption of the $D s g 3$ gene was established from animals generously donated to The Induced Mutant Resource of The Jackson Laboratory by John R. Stanley (University of Pennsylvania). We thank Peter Koch (Baylor College of Medicine) for providing the primer sequences used for typing $D s g 3^{\text {null }}$ mice, and Masayuki Amagai (Keio University, Tokyo, Japan) for providing the Dsg1-Ig-His, Dsg3-His and Dsg3-Ig-His baculoviruses used to produce the respective baculoproteins for immunoadsorption experiments. This work was supported through the International Pemphigus Research Fund (S.A. Grando) and a grant (CA20408) from the National Institutes of Health (L.D. Shultz).

1. Nguyen, V.T., et al. 1998. The pathophysiological significance of nondesmoglein targets of pemphigus autoimmunity. Pemphigus vulgaris and foliaceus patients develop antibodies against keratinocyte cholinergic receptors. Arch. Dermatol. 134:971-980.

2. Stanley, J.R., Yaar, M., Hawley-Nelson, P., and Katz, S.I. 1982. Pemphigus antibodies identify a cell surface glycoprotein synthesized by human and mouse keratinocytes. J. Clin. Invest. 70:281-288.

3. Stanley, J.R., Koulu, L., and Thivolet, C. 1984. Distinction between epidermal antigens binding pemphigus vulgaris and pemphigus foliaceus autoantibodies. J. Clin. Invest. 74:313-320.

4. Stanley, J.R. 1989. Pemphigus and pemphigoid as paradigms of organspecific, autoantibody-mediated diseases. J. Clin. Invest. 83:1443-1448.

5. Amagai, M., Klaus-Kovtun, V., and Stanley, J.R. 1991. Autoantibodies against a novel epithelial cadherin in pemphigus vulgaris, a disease of cell adhesion. Cell. 67:869-877.

6. Stanley, J.R., Koulu, L., Klaus-Kovtun, V., and Steinberg, M.S. 1986. A monoclonal antibody to the desmosomal glycoprotein desmoglein I binds the same polypeptide as human autoantibodies in pemphigus foliaceus. J. Immunol. 136:1227-1230.

7. Korman, N.J., Eyre, R.W., Klaus-Kovtun, V., and Stanley, J.R. 1989. Demonstration of an adhering-junction molecule (plakoglobin) in the autoantigens of pemphigus foliaceus and pemphigus vulgaris. $N$. Engl. J. Med. 321:631-635.

8. Hashimoto, T. 1993. Cadherins and blistering skin diseases. Curr. Opin. Dermatol. 2:244-249.

9. Amagai, M. 1995. Adhesion molecules. I. Keratinocyte-keratinocyte interactions; cadherins and pemphigus. J. Invest. Dermatol. 104:146-152

10. Stanley, J.R. 1995. Defective cell-cell adhesion in the epidermis. Ciba Found. Symp. 189:107-120.

11. Stanley, J.R. 1993. Cell adhesion molecules as targets of autoantibodies in pemphigus and pemphigoid, bullous diseases due to defective epidermal cell adhesion. Adv. Immunol. 53:291-325.

12. Hashimoto, T., Amagai, M., Garrod, D.R., and Nishikawa, T. 1995 Immunofluorescence and immunoblot studies on the reactivity of pemphigus vulgaris and pemphigus foliaceus sera with desmoglein 3 and desmoglein 1. Epithelial Cell Biol. 4:63-69.

13. Amagai, M., Koch, P.J., Nishikawa, T., and Stanley, J.R. 1996. Pemphigus vulgaris antigen (desmoglein 3 ) is localized in the lower epider- mis, the site of blister formation in patients. J. Invest. Dermatol. 106:351-355.

14. Rickman, L., et al. 1999. N-terminal deletion in a desmosomal cadherin causes the autosomal dominant skin disease striate palmoplantar keratoderma. Hum. Mol. Genet. 8:971-976.

15. Allen, E., Yu, Q.C., and Fuchs, E. 1996. Mice expressing a mutant desmosomal cadherin exhibit abnormalities in desmosomes, proliferation, and epidermal differentiation. J. Cell. Biol. 133:1367-1382.

16. Montagutelli, X., Lalouette, A., Boulouis, H.J., Guenet, J.L., and Sundberg, J.P. 1997. Vesicle formation and follicular root sheath separation in mice homozygous for deleterious alleles at the balding ( $\mathrm{bal}$ ) locus. J. Invest. Dermatol. 109:324-328.

17. Koch, P.J., et al. 1997. Targeted disruption of the pemphigus vulgaris antigen (desmoglein 3 ) gene in mice causes loss of keratinocyte cell adhesion with a phenotype similar to pemphigus vulgaris. J. Cell Biol. 137:1091-1102.

18. Lenox, J.M., et al. 2000. Postnatal lethality of P-Cadherin/Desmoglein 3 double knockout mice: demonstration of a cooperative effect of these cell adhesion molecules in tissue homeostasis of stratified squamous epithelia. J. Invest. Dermatol. 114:948-952.

19. Amagai, M., Karpati, S., Prussick, R., Klaus-Kovtun, V., and Stanley, J.R. 1992. Autoantibodies against the amino-terminal cadherin-like binding domain of pemphigus vulgaris antigen are pathogenic. J. Clin. Invest. 90:919-926.

20. Karpati, S., Amagai, M., Prussick, R., Cehrs, K., and Stanley, J.R. 1993. Pemphigus vulgaris antigen, a desmoglein type of cadherin, is localized within keratinocyte desmosomes. J. Cell Biol. 122:409-415.

21. Amagai, M., Hashimoto, T., Shimizu, N., and Nishikawa, T. 1994. Absorption of pathogenic autoantibodies by the extracellular domain of pemphigus vulgaris antigen (Dsg3) produced by baculovirus. J. Clin. Invest. 94:59-67.

22. Amagai, M., Hashimoto, T., Green, K.J., Shimizu, N., and Nishikawa, T. 1995. Antigen-specific immunoadsorption of pathogenic autoantibodies in pemphigus foliaceus. J. Invest. Dermatol. 104:895-901.

23. Amagai, M., Nishikawa, T., Nousari, H.C., Anhalt, G.J., and Hashimoto, T. 1998. Antibodies against desmoglein 3 (pemphigus vulgaris antigen) are present in sera from patients with paraneoplastic pemphigus and cause acantholysis in vivo in neonatal mice. J. Clin. Invest. 102:775-782.

24. Nguyen, V.T., Ndoye, A., and Grando, S.A. 2000. Novel human $\alpha 9$ acetylcholine receptor regulating keratinocyte adhesion is targeted by pemphigus vulgaris autoimmunity. Am. J. Pathol. 157:1377-1391.

25. Labib, R.S., Rock, B., Robledo, M.A., and Anhalt, G.J. 1991. The calcium-sensitive epitope of pemphigus foliaceus antigen is present on a murine tryptic fragment and constitutes a major antigenic region for human autoantibodies. J. Invest. Dermatol. 96:144-147.

26. Eyre, R.W., and Stanley, J.R. 1988. Identification of pemphigus vulgaris antigen extracted from normal human epidermis and comparison with pemphigus foliaceus antigen. J. Clin. Invest. 81:807-812.

27. Hashimoto, T., Ogawa, M.M., Konohana, A., and Nishikawa, T. 1990. Detection of pemphigus vulgaris and pemphigus foliaceus antigens by immunoblot analysis using different antigen sources. J. Invest. Dermatol. 94:327-331.

28. Hashimoto, T., Konohana, A., and Nishikawa, T. 1991. Immunoblot assay as an aid to the diagnoses of unclassified cases of pemphigus. Arch. Dermatol. 127:843-847.

29. Dmochowski, M., Hashimoto, T., and Nishikawa, T. 1992. The analysis of IgG subclasses of anti-intercellular antibodies in pemphigus by an immunoblot technique. Arch. Dermatol. Res. 284:309-311.

30. Emery, D.J., et al. 1995. Pemphigus foliaceus and pemphigus vulgaris autoantibodies react with the extracellular domain of desmoglein-1. J. Invest. Dermatol. 104:323-328.

31. Ding, X., et al. 1997. Mucosal and mucocutaneous (generalized) pemphigus vulgaris show distinct autoantibody profiles. J. Invest. Dermatol. 109:592-596.

32. Mahoney, M.G., et al. 1999. Explanations for the clinical and microscopic localization of lesions in pemphigus foliaceus and vulgaris. $J$. Clin. Invest. 103:461-468.

33. Beutner, E.H., Chorzelski, T.P., and Jablonska, S. 1985. Immunofluorescence tests. Clinical significance of sera and skin in bullous diseases. Int. J. Dermatol. 24:405-421.

34. Grando, S.A., and Dahl, M.V. 1993. Activation of keratinocyte muscarinic acetylcholine receptors reverses pemphigus acantholysis. J. Eur. Acad. Dermatol. Venereol. 2:72-86.

35. Nguyen, V.T., Ndoye, A., and Grando, S.A. 2000. Pemphigus vulgaris antibody identifies pemphaxin: a novel keratinocyte annexin-like molecule binding acetylcholine. J. Biol. Chem. 275:29466-29476.

36. Olague-Alcala, M., Giudice, G.J., and Diaz, L.A. 1994. Pemphigus foliaceus sera recognize an $\mathrm{N}$-terminal fragment of bovine desmoglein 1. J. Invest. Dermatol. 102:882-885.

37. Amagai, M., Tsunoda, K., Zillikens, D., Nagai, T., and Nishikawa, T. 
1999. The clinical phenotype of pemphigus is defined by the antidesmoglein autoantibody profile. J. Am. Acad. Dermatol. 40:167-170.

38. Lenz, P., Amagai, M., Volc-Platzer, B., Stingl, G., and Kirnbauer, R. 1999. Desmoglein 3-ELISA: a pemphigus vulgaris-specific diagnostic tool. Arch. Dermatol. 135:143-148.

39. Amagai, M., et al. 1999. Usefulness of enzyme-linked immunosorbent assay using recombinant desmogleins 1 and 3 for serodiagnosis of pemphigus. Br. J. Dermatol. 140:351-357.

40. Schiltz, J.R., and Michel, B. 1976. Production of epidermal acantholysis in normal human skin in vitro by the IgG fraction from pemphigus serum. J. Invest. Dermatol. 67:254-260.

41. Swanson, D.L., and Dahl, M.V. 1983. Methylprednisolone inhibits pemphigus acantholysis in skin cultures. J. Invest. Dermatol. 81:258-260.

42. Anhalt, G.J., Labib, R.S., Voorhees, J.J., Beals, T.F., and Diaz, L.A. 1982. Induction of pemphigus in neonatal mice by passive transfer of IgG from patients with the disease. N. Engl. J. Med. 306:1189-1196.

43. Nguyen, V., Kadunce, D.P., Hendrix, J.D., Gammon, W.R., and Zone, J.J. 1993. Inhibition of neutrophil adherence to antibody by dapsone: a possible therapeutic mechanism of dapsone in the treatment of $\operatorname{IgA}$ dermatoses. J. Invest. Dermatol. 100:349-355.

44. Ding, X., Diaz, L.A., Fairley, J.A., Guidice, G.J., and Liu, Z. 1999. The anti-desmoglein 1 autoantibodies in pemphigus vulgaris sera are pathogenic. J. Invest. Dermatol. 112:739-743.

45. Wilgram, G.F., Caulfield, J.B., and Lever, W.F. 1961. An electron microscopic study of acantholysis in pemphigus vulgaris. J. Invest. Dermatol. 36:373-382.

46. Cohen, L.M., Skopicki, D.K., Harrist, T.J., and Clark, W.H., Jr. 1997. Noninfectious vesicobullous and vesicopustular diseases. In Lever's histopathology of the skin. D. Elder, R. Elenitas, C. Jaworsky, and B.J. Johnson, editors. Lippincott-Raven. Philadelphia, Pennsylvania, USA. 209-252.

47. Udey, M.C., and Stanley, J.R. 1999. Pemphigus: diseases of antidesmosomal autoimmunity. JAMA. 282:572-576.

48. Mahoney, M.G., et al. 1998. Explanation for localization of blisters in pemphigus patients. J. Invest. Dermatol. 110:499. (Abstr.)

49. Bellone, A.G., and Leone, V. 1956. Ricerche sull'influenza esercitata da sieri di soggetti sani o affetti da pemfigo su pelle umana normale e pemfigosa coltivata "in vitro". G. Ital. Dermatol. Minerva Dermatol. 97:97-109.

50. Farb, R.M., Dykes, R., and Lazarus, G.S. 1978. Anti-epidermal-cell-surface pemphigus antibody detaches viable epidermal cells from culture plates by activation of proteinase. Proc. Natl. Acad. Sci. USA. 75:459-463.

51. Patel, H.P., Diaz, L.A., Anhalt, G.J., Labib, R.S., and Takahashi, Y. 1984 Demonstration of pemphigus antibodies on the cell surface of murine epidermal cell monolayers and their internalization. J. Invest. Derma- tol. 83:409-415.

52. Beutner, E., and Jordon, R. 1964. Demonstration of skin antibodies in sera of pemphigus vulgaris patients by indirect immunofluorescent staining. Proc. Soc. Exp. Biol. Med. 117:505-510.

53. Johnston, R.F., Pickett, S.C., and Barker, D.L. 1990. Autoradiography using storage phosphor technology. Electrophoresis. 11:355-360.

54. Zouboulis, C.C., and Tavakkol, A. 1994. Storage phosphor imaging technique improves the accuracy of RNA quantitation using ${ }^{32} \mathrm{P}$ labeled cDNA probes. Biotechniques. 16:290-292, 294.

55. Abreu-Velez, A.M., et al. 1997. Characterization of a $45 \mathrm{kD}$ epidermal tryptic peptide recognized by pemphigus foliaceus sera. J. Invest. Dermatol. 108:541. (Abstr.)

56. Ishii, K., et al. 1997. Characterization of autoantibodies in pemphigus using antigen-specific enzyme-linked immunosorbent assays with baculovirus-expressed recombinant desmogleins. J. Immunol. 159:2010-2017.

57. Kitajima, Y., Aoyama, Y., and Seishima, M. 1999. Transmembrane signaling for adhesive regulation of desmosomes and hemidesmosomes, and for cell-cell detachment induced by pemphigus IgG in cultured keratinocytes: involvement of protein kinase C. J. Invest. Dermatol. Symp. Proc. 4:137-144.

58. Aoyama, Y., and Kitajima, Y. 1999. Pemphigus vulgaris-IgG causes a rapid depletion of desmoglein 3 (Dsg3) from the triton $X-100$ soluble pools, leading to the formation of Dsg3-depleted desmosomes in a human squamous carcinoma cell line, DJM-1 cells. J. Invest. Dermatol. 112:67-71.

59. Aoyama, Y., Owada, M.K., and Kitajima, Y. 1999. A pathogenic autoantibody, pemphigus vulgaris-IgG, induces phosphorylation of desmoglein 3 , and its dissociation from plakoglobin in cultured keratinocytes. Eur. J. Immunol. 29:2233-2240.

60. Xue, W. 1999. Pemphigus vulgaris IgG regulates expression of urokinase receptor and junctional proteins that may contribute to acantholysis. J. Am. Acad. Dermatol. 41:462-463.

61. Benz, J., and Hofmann, A. 1997. Annexins: from structure to function. Biol. Chem. 378:177-183.

62. Grando, S.A. 1997. Biological functions of keratinocyte cholinergic receptors. J. Invest. Dermatol. Symp. Proc. 2:41-48.

63. Vasioukhin, V., Bauer, C., Yin, M., and Fuchs, E. 2000. Directed actin polymerization is the driving force for epithelial cell-cell adhesion. Cell. 100:209-219.

64. Hu, Z., et al. 2000. Mutations in ATP2C1, encoding a calcium pump, cause Hailey-Hailey disease. Nat. Genet. 24:61-65.

65. Sakuntabhai, A., et al. 1999. Mutations in ATP2A2, encoding a Ca ${ }^{2+}$ pump, cause Darier disease. Nat. Genet. 21:271-277.

66. Grando, S.A. 2000. Autoimmunity to keratinocyte acetylcholine receptors in pemphigus. Dermatology (Basel). 201:290-295. 